\title{
Alopecia Areata in Twins With Autoimmune Thyroiditis: Personal Observations
}

\author{
Giusy Schipani ${ }^{1}$, Stefano Dastoli ${ }^{1}$, Elisabetta Scali ${ }^{1}$, Luigi Bennardo ${ }^{1}$, \\ Martina Silvestri ${ }^{1}$, Steven Paul Nisticò ${ }^{1}$
}

1 Dermatology Unit, Department of Health Sciences, Magna Graecia University, Catanzaro, Italy

Key words: autoimmune thyroiditis, alopecia areata, twins

Citation: Schipani G, Dastoli S, Scali E, Bennardo L, Silvestri M, Nisticò SP. Alopecia areata in twins with autoimmune thyroiditis: personal observations. Dermatol Pract Concept. 2019;9(3):241-243. DOI: https://doi.org/10.5826/dpc.0903a21

Accepted: January 23, 2019; Published: July 31, 2019

Copyright: $\odot 2019$ Schipani et al. This is an open-access article distributed under the terms of the Creative Commons Attribution License, which permits unrestricted use, distribution, and reproduction in any medium, provided the original author and source are credited.

Funding: None.

Competing interests: The authors have no conflicts of interest to disclose.

Authorship: All authors have contributed significantly to this publication.

Corresponding author: Luigi Bennardo, MD, Via Serra Tancredi 287010 Lattarico (CS), Italy. Email: luigibennardo10@gmail.com

\section{Introduction}

Two 15 -year-old female monozygotic twins affected by alopecia areata (AA) and thyroiditis presented to our clinical attention. Their family history was negative for thyroiditis. AA was localized on their occipital and parietal regions, forming an ophiasis pattern.

\section{Case Presentation}

Dermatological examination of the first twin (GC, twin A, Figure 1) showed wave-shaped hair-loss patches localized predominantly on the right side of the parieto-temporooccipital scalp. The disease started at age 4; alopecia was widespread to a large part of the scalp. Beginning at age 14, twin A was treated with systemic and topical corticosteroids and today presents the current clinical features. The second twin (GG, twin B, Figure 2), instead, since age 14 presented a framework of localized, round, small alopecia localized in the temporo-occipital area. During clinical examination, a patch of hair loss was evident on the occipital scalp of both twins, without other skin lesions or signs of inflammation; occasional itch was present.

After our consultation, the twins underwent blood analysis. The results of the laboratory tests were suggestive of autoimmune thyroiditis in both patients, as the autoantibody values were very high (twin A: thyroglobulin antibodies 28.7 $\mathrm{IU} / \mathrm{mL}$, thyroperoxidase antibodies $617.46 \mathrm{IU} / \mathrm{mL}$; twin B: thyroglobulin antibodies $44.51 \mathrm{IU} / \mathrm{mL}$, thyroperoxidase antibodies $>1,000.00 \mathrm{IU} / \mathrm{mL}$ ); furthermore, twin A also had above-average blood test results: total antioxidant status 494 IU/mL, hemoglobin $11.6 \mathrm{~g} / \mathrm{dL}$, transferrin $398 \mathrm{mg} / \mathrm{mL}$, and ferritin $6.67 \mathrm{ng} / \mathrm{mL}$; twin B also had elevated total antioxidant status (407 IU/mL) and vitamin D (10 ng/mL) levels. The remaining tests were negative for both patients.

Treatment with oral betamethasone $2 \mathrm{mg} /$ day was started for both twins for 1 month when they were 14 years old. It was then reduced to $2 \mathrm{mg}$ twice a week in association with vasodilatory and antiseptic lotions of the scalp for 2 months. This therapy led to a partial remission of dermatological manifestations in both patients. An endocrinological consultation was also recommended to better evaluate thyroid malfunctioning. 


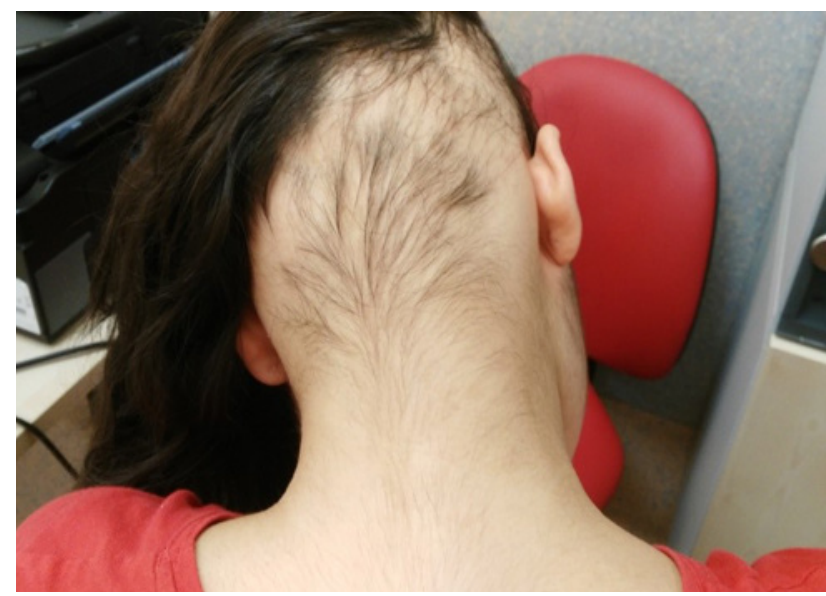

Figure 1. AA in twin A. [Copyright: $\odot 2019$ Schipani et al.]

\section{Conclusions}

Association between autoimmune disease and AA has been widely discussed. Several studies have revealed a high prevalence of thyroid disorders in patients with AA. Screening for autoimmune thyroiditis and thyroid function should be done in all patients with these cutaneous disorders for the early identification of this disease.

Recently Lortkipanidze et al [1] described a case of AA and alopecia universalis occurring in identical twins in the same area of the scalp, forming an ophiasis pattern. Previously Dogra et al [2] focused their attention on the occurrence of AA in the members of the same family, supporting the hypothesis that the patients with AA are genetically predisposed to develop this kind of disease.

In patients affected by autoimmune thyroid diseases, the functions of the different skin cell types may be affected not only by variation in thyroid hormone levels but also by the presence of thyroid-specific autoantibodies [3]. Thyroid hormones act on epidermal differentiation and their effects are particularly important for the function of sebaceous, eccrine, and apocrine glands; growth of hair follicles; and synthesis of proteo- and glycosaminoglycans by dermal fibroblasts [4]. Thyroid hormones were found to induce differentiation and apoptosis and inhibit clonal growth of hair follicle epithelial stem cells [5]. Moreover, the immunoregulatory genes that predispose to autoimmune thyroiditis (FOXP3, CD25, CD40, CTLA4, the HLA genes, PTPN22, among other emerging immunoregulatory genes) have a critical role in the development of an effective immune response including self-tolerance, humoral immunity, and cell-mediated immunity. Recent data show that the pathogenesis of autoimmune thyroiditis is mediated by TH1, TH2, and TH17 subtypes. TH17 lymphocytes are mainly characterized by the synthesis of interleukin (IL)-17A, IL-17F, IL-21, IL-22, and IL-47, which contribute to the release of other proinflammatory mediators by stimu-

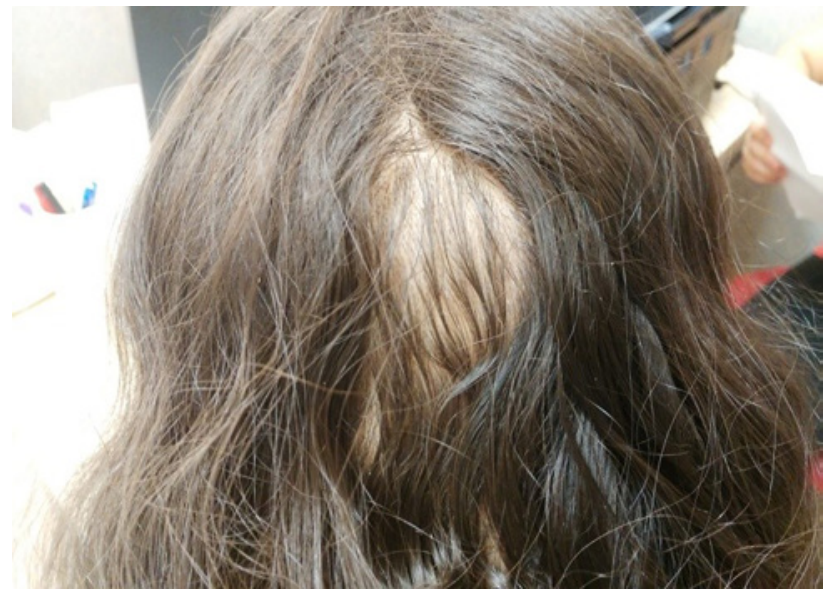

Figure 2. AA in twin B. [Copyright: (O2019 Schipani et al.]

lating epithelial cells, fibroblasts, and macrophages. In addition, a role of Treg lymphocytes has been hypothesized: they have an immunosuppressive effect and contribute to prevent autoimmune responses. Therefore, defects in Treg cell number and/or function may contribute to the development of autoimmune diseases such as AA [6]. Different immune-cell lines including plasmocytic dendritic cells, natural killer (NK) cells, and $\mathrm{T}$ cells, along with key molecules such as interferon- $\gamma$, IL-15, MICA, and NKG2D, have been identified as contributing to the autoimmune process in AA [7]. Genome-wide association studies provide evidence for the involvement of both innate and acquired immunity in the pathogenesis, and mechanistic studies in mouse models of AA have specifically implicated an IFN- $\gamma$-driven immune response, including IFN$\gamma$, IFN- $\gamma$-induced chemokines, and cytotoxic CD8 T cells as the main drivers of disease pathogenesis [8]. Low expression of major histocompatibility complex class I and II molecules and high expression of macrophage migration inhibitory factor, an NK cell inhibitor, prevent infiltration of a subset of $\mathrm{T}$ lymphocytes from the hair follicle of healthy individuals, but aggregations of CD 56+/NKG2D+ NK cells are found around hair follicles from patients with AA [9].

Based on the literature data, which suggest a common activation of different immune patterns, and on the data obtained by our clinical case, we can say that AA should be considered a warning manifestation for other distinct diseases such as ones that affect the thyroid. In this unusual case, a genetic study to support the relationship between AA and autoimmunity may be useful.

\section{References}

1. Lortkipanidze N, Zlotogorski A, Ramot Y. Two episodes of simultaneous identical alopecia areata in identical twins. Int J Trichology. 2016;8(1):47-48.

2. Dogra D, Sood A, Khaitan BK. Alopecia areata in identical twins. Indian J Dermatol Venereol Leprol. 1996;62(3):199. 
3. Cianfarani F, Baldini E, Cavalli A, et al. TSH receptor and thyroid-specific gene expression in human skin. J Invest Dermatol. 2010;130:93-101.

4. Slominski AT, Zmijewski MA, Skobowiat C, Zbytek B, Slominski RM, Steketee JD. Sensing the environment: regulation of local and global homeostasis by the skin's neuroendocrine system. Adv Anat Embryol Cell Biol. 2012;212: v, vii, 1-115.

5. Tiede S, Bohm K, Meier N, Funk W, Paus R. Endocrine controls of primary adult human stem cell biology: thyroid hormones stimulate keratin 15 expression, apoptosis, and differentiation in human hair follicle epithelial stem cells in situ and in vitro. Eur J Cell Biol. 2010; 89(10): 769-777.
6. Ramos-Leví AM, Marazuela M. Pathogenesis of thyroid autoimmune disease: the role of cellular mechanisms. Endocrinol Nutr. 2016;63(8):421-429.

7. Rajabi F, Drake LA, Senna MM, Rezaei N. Alopecia areata: a review of disease pathogenesis. Br J Dermatol. 2018;179(5):10331048.

8. Trüeb RM, Dias MFRG. Alopecia areata: a comprehensive review of pathogenesis and management. Clin Rev Allergy Immunol. 2018;54(1):68-87.

9. Pratt CH, King LE Jr, Messenger AG, Christiano AM, Sundberg JP. Alopecia areata. Nat Rev Dis Primers. 2017;3:17011. 